\title{
Morphology impact on the absorption behaviour of post-thermally treated tris(8-hydroxyquinoline) gallium films
}

\author{
Fahmi Fariq Muhammad \\ Soft Materials and Devices Research Laboratory, Department of Physics, Faculty of Science \& \\ Health, Koya University, Koya, Kurdistan Regional Government-Iraq \\ Email address: fahmi.fariq@koyauniversity.org OR fahmi982@gmail.com
}

Tel.: +9647501168841

Keywords: Gaq3, annealing, FESEM, XRD, morphology.

\begin{abstract}
This work reports on the impact of surface morphology on the optical absorption of vacuum deposited tris(8-hydroxyquinoline) gallium (Gaq3) films. Morphological investigation was performed for films treated under nitrogen gas in the temperature range from $85{ }^{\circ} \mathrm{C}$ to $255{ }^{\circ} \mathrm{C}$. The results of field emission scanning electron microscopy (FESEM) and $\mathrm{x}$-ray diffraction (XRD) technique ascertained the formation of amorphous nanostructures. Considerable modification in the absorption behaviour of Gaq3 films was observed upon morphological changes. The results of these modifications were ascribed to the impact of morphological variations among the surface of Gaq3 films.
\end{abstract}

\section{INTRODUCTION}

Tris(8-hydroxyquinoline) gallium (Gaq3) is a well-known organometallic material widely used in the development of organic electronics devices such as organic light emitting diodes (OLEDs) and organic solar cells (OSCs) [1-4]. It was reported that the utilization of Gaq3 in OLEDs has improved the device performance in comparison to that of the Alq3 based ones [5]. Investigations on the Gaq3 properties received considerable attention in both theoretical and practical aspects [6-9]. Improvement in the Gaq3 properties is crucial for its application in OLED and/or OSC devices. Various strategies were undertaken by researchers to enhance the physical behaviour of organic materials, namely thermal annealing process [10-12], in-situ controlled substrate temperature [13] and the use of different substrates [14]. Thermal evaporation under cold trap at different working temperatures and pressures was examined to fabricate crystalline Alq 3 and Gaq3 nanostructures on silicon substrates $[13,15]$. It was found that this has led to enhance the photoluminescence action in the films, but the crystallized structure may produce undesired light scattering or leak current in OLED application $[16,17]$. This research work is conducted to apply the post-thermal annealing process under nitrogen gas to modify the surface morphology of vacuum deposited Gaq3 film. The impact of this surface modification on the absorption behaviour was then investigated. It was found that this process is a viable tool to fabricate nanostructures along the surface of the films and can be a novel route to modify the absorption response in Gaq 3 films.

\section{MATERIALS AND METHODS}

Tris (8-hydroxyquinolinate) gallium (Gaq3) was purchased from Sigma-Aldrichin powder form and used as received. Figure 1 shows the chemical structure of Gaq3. Films of Gaq3 were thermally evaporated onto pre-cleaned quartz substrates by utilizing a home-made thermal evaporator under a pressure of about $10^{-4}$ mbar. The quartz slides were cleaned ultrasonically with Deacon $^{\circledR}$ Neutracon foam solution for 15 minutes followed by rinsing in acetone, ethanol and distilled water for 10 minutes in ultrasonic bath, respectively. Finally, the quartz slides were dried thoroughly by blowing the nitrogen gas. 


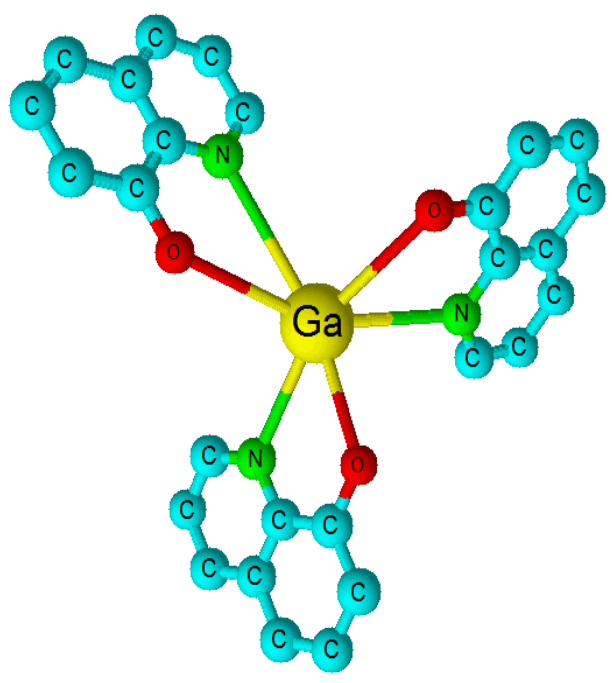

Figure 1: Three dimensional view of Gaq3 structure.

Gaq3 films with thickness $\sim 764 \mathrm{~nm}$ were post-thermally annealed under flowing nitrogen gas in a barrel furnace. The process was set for 10 minutes at temperatures of $85{ }^{\circ} \mathrm{C}, 160{ }^{\circ} \mathrm{C}, 235{ }^{\circ} \mathrm{C}$ and $255^{\circ} \mathrm{C}$. Field emission scanning electronic microscopy technique (FESEM, Quanta 200F) was used to capture the surface morphology of the films. X-ray diffraction technique (a Bruker AXS) with $\mathrm{Cu} \mathrm{K}$ radiation of wavelength $\lambda=1.5406 \mathrm{~A}^{\circ}$ as a source was utilized to measure the XRD patterns for the films. The absorbance of the films was recorded at room temperature using Jasco V-570 UV-Vis-NIR spectrophotometer in the wavelength range from 200 to $2500 \mathrm{~nm}$.

\section{RESULTS AND DISCUSSION}

Figure 2 shows the FESEM images of untreated and post-thermally treated Gaq 3 films under nitrogen gas. Noticeably, the surface morphology of the films has not been pronouncedly affected by temperatures under $160{ }^{\circ} \mathrm{C}$, while temperatures of 160 and $235{ }^{\circ} \mathrm{C}$ were highly effective to produce clear modification in the molecular distribution of the films, thereby growing nanostructured rods. The growth of nanostructure along the surface of Gaq3 at prescribed temperatures can be understood by means of molecular migration, in which the Gaq3 molecules migrate and pile up by acquiring enough thermal energy from the appropriate heating treatment [14]. It is worth mentioning that annealing process beyond $255^{\circ} \mathrm{C}$ has made the rods to be degraded and cross linked. This is where the formation of crystalline portion in the films was ascertained as shown in Figure 3. The hard heating temperature of $310^{\circ} \mathrm{C}$ produced dark spots along the surface of the films indicating the presence of high portion for Gaq3 to be melted and sublimate ultimately. 

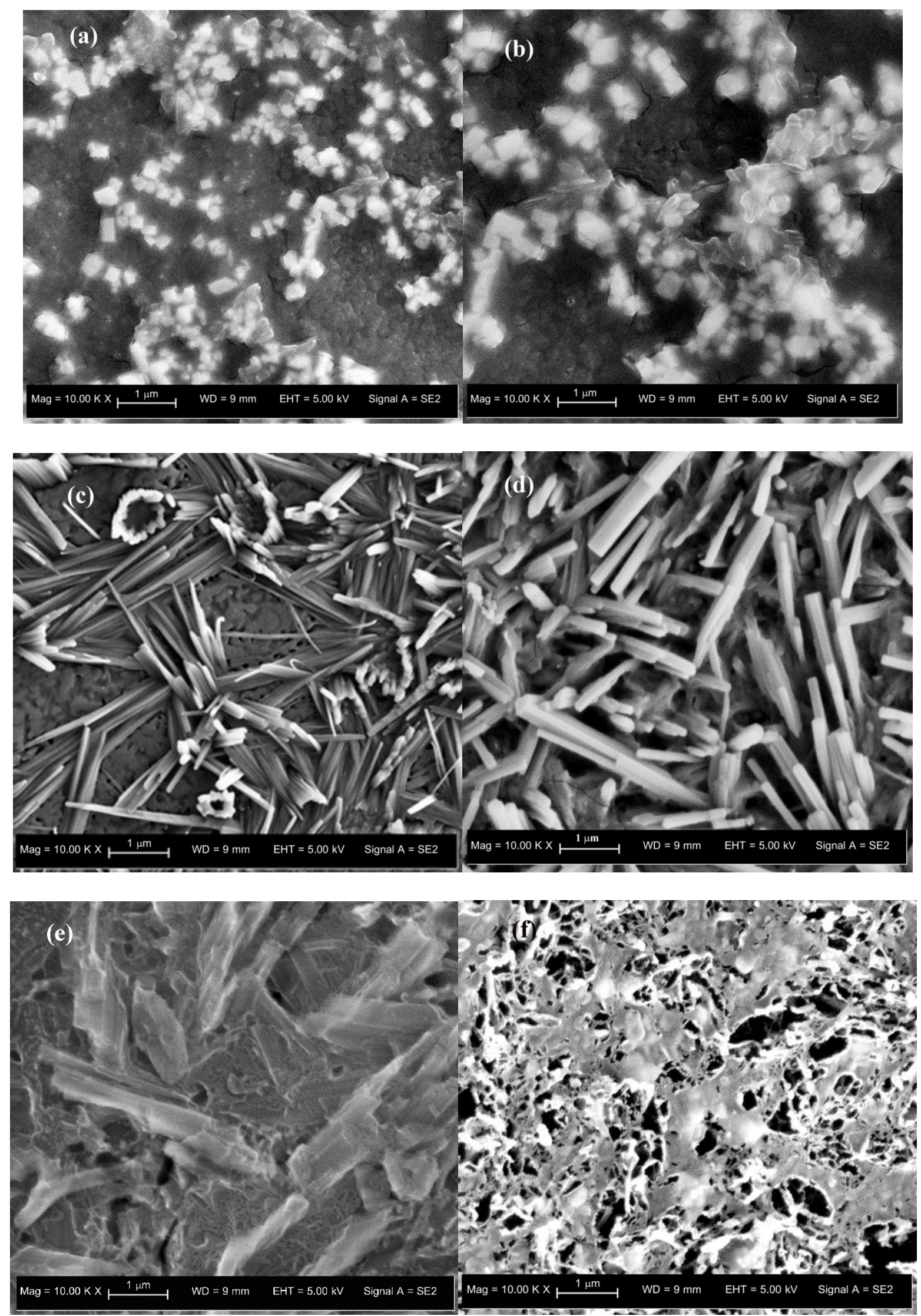

Figure 2: FESEM images of untreated Gaq3 films (a) and post-thermally treated ones at $85^{\circ} \mathrm{C}(\mathrm{b}), 160^{\circ} \mathrm{C}$ (c), $235^{\circ} \mathrm{C}$ (d), $255^{\circ} \mathrm{C}$ (e) and $310^{\circ} \mathrm{C}$ (f) under nitrogen gas.

Figure 3 shows the XRD results recorded for post-thermally treated films at 235 and $255{ }^{\circ} \mathrm{C}$, by which the fortified and degraded nanostructures were formed, respectively. The broad absorption band in between 15 to 30 degrees is referred to that of the quartz substrates. Nevertheless, crystalline region was seen to appear for the films annealed at $255^{\circ} \mathrm{C}$. The intense diffraction peak 
at $2 \theta=15.9^{\circ}$ confirming the crystallinity was estimated to correspond with a periodicity of $\mathrm{d}=$ $0.557 \mathrm{~nm}$.

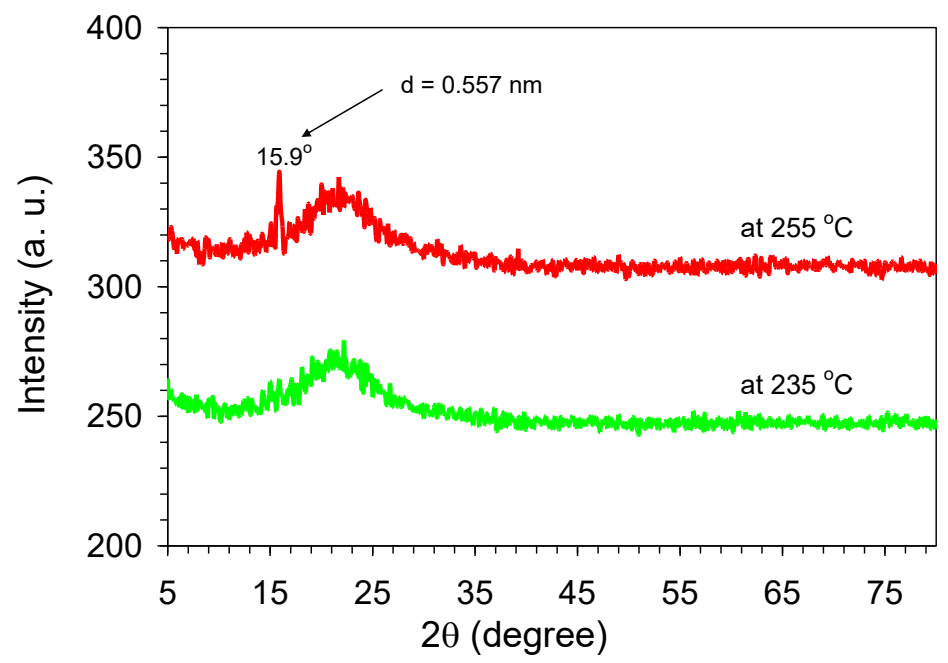

Figure 3: The XRD patterns for the Gaq3 films annealed at 235 and $255{ }^{\circ} \mathrm{C}$.

The absorption coefficient $(\alpha)$ for the films was determined by using the relation $\alpha=2.303 \mathrm{~A} / \mathrm{t}$ [18], where $A$ is the absorbance of the film and $t$ its thickness. Figure 4 shows the absorption coefficient of the pristine and annealed films in the temperature range from $85{ }^{\circ} \mathrm{C}$ to $255{ }^{\circ} \mathrm{C}$ under nitrogen gas for 10 minute. Two main peaks were found for the untreated film; the first peak is at photon energy of about $3.14 \mathrm{eV}$, while the second one is located in the ultraviolet region with relatively broad and intense at about $4.67 \mathrm{eV}$. These peaks were assigned to the existence of electronic transitions from $\pi \rightarrow \pi^{*}$ and $4 p \rightarrow \pi^{*}$ orbital energy bands, respectively [9]. One can observe that increased annealing temperature has made the intensity of visible band to be lowered in opposite trend to that of the ultraviolet band. Nevertheless, at temperature of $235^{\circ} \mathrm{C}$, the absorption spectrum has become broader covering the whole UV range and part of the visible region. The decrease in the UV peak was also found for Alq3 films [19] and it was attributed to the change in chemical nature of Alq3 film due to its exposure to atmosphere [20]. In this work, Gaq3 films were annealed under nitrogen gas. So the impact of atmospheric exposure can be ignored. Alternatively, nanostructure formation resulted from morphological variation can be responsible for this great modification in optical absorption. This can be elaborated as within the broad distribution of molecular packings, favourable $\pi-\pi$ overlaps between facing ligands may occur [21], thereby involving interaction and energy exchanges at molecular level which have consequences on the spectral properties of the molecules [22].

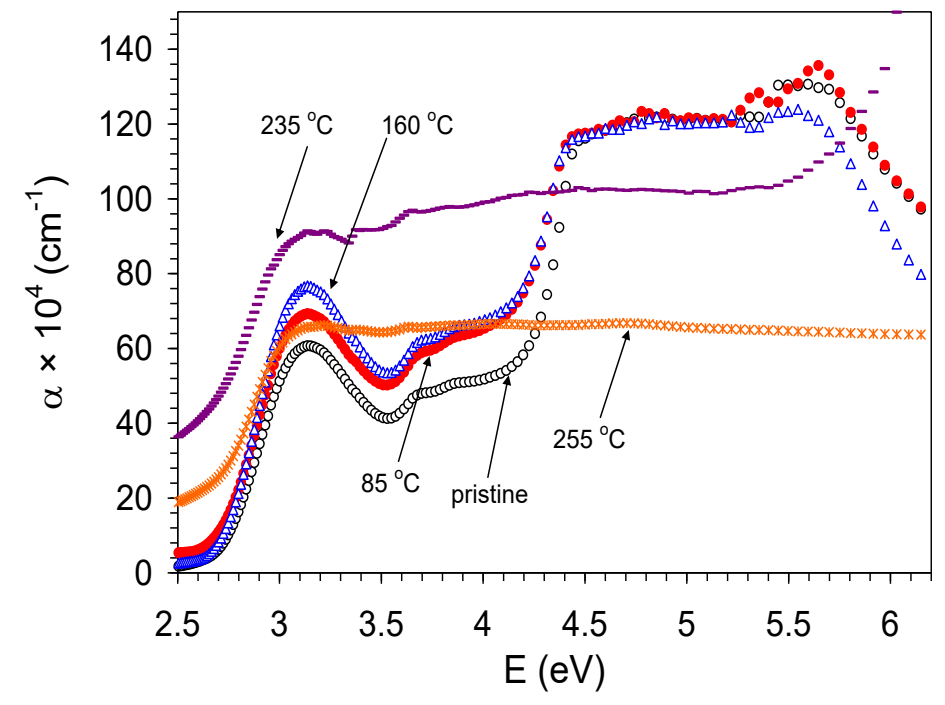

Figure 4: Absorption coefficient for untreated and post-thermally treated films of Gaq3 under nitrogen gas. 


\section{CONCLUSIONS}

Variation in the absorption response of Gaq3 films was obtained through the impact of morphological modification which was achieved by means of thermal treatment under nitrogen gas in the temperature range from $85{ }^{\circ} \mathrm{C}$ to $255^{\circ} \mathrm{C}$. The formation of amorphous nanostructures among the surface of Gaq3 films was confirmed through FESEM and XRD techniques. A broad absorption spectrum was noticed at treated temperature of $235^{\circ} \mathrm{C}$.

\section{Acknowledgement}

The author would like to thank Department of Physics, Koya University, for the administrative support to this work.

\section{References}

[1] P.-C. Kao, S.-Y. Chu, H.-H. Huang, Z.-L. Tseng, Y.-C. Chen, Thin Solid Films, 517 (2009) 5301-5304.

[2] P. Vivo, J. Jukola, M. Ojala, V. Chukharev, H. Lemmetyinen, Solar Energy Materials and Solar Cells, 92 (2008) 1416-1420.

[3] F.F. Muhammad, Journal of Technology Innovations in Renewable Energy, 3 (2014) 1-8.

[4] M.A. Mohd Sarjidan, S.H. Basri, N.K. Za'Aba, M.S. Zaini, W.H. Abd Majid, Bull. Mater. Sci., 38 (2015) 235-239.

[5] L. Wang, X. Jiang, Z. Zhang, S. Xu, Displays, 21 (2000) 47-49.

[6] G. Gahungu, J. Zhang, Journal of Molecular Structure: THEOCHEM, 755 (2005) 19-30.

[7] J. Zhang, G. Frenking, Chemical Physics Letters, 394 (2004) 120-125.

[8] I. Hernández, W.P. Gillin, The Journal of Physical Chemistry B, 113 (2009) 14079-14086.

[9] F.F. Muhammad, A.I. Abdul Hapip, K. Sulaiman, Journal of Organometallic Chemistry, 695 (2010) 2526-2531.

[10] R. Singh, J. Kumar, R.K. Singh, A. Kaur, K.N. Sood, R.C. Rastogi, Polymer, 46 (2005) 91269132.

[11] S. Satapathy, S. Pawar, P.K. Gupta, K.B.R. Varma, Bull. Mater. Sci., 34 (2011) 727-733.

[12] R. Somashekar, R. Gopalkrishna Urs, Bull. Mater. Sci., 14 (1991) 87-91.

[13] C.-P. Cho, C.-Y. Yu, T.-P. Perng, Nanotechnology, 17 (2006) 5506-5510.

[14] P. Kumar, Sonia, R.K. Patel, C. Prakash, T.C. Goel, Materials Chemistry and Physics, 110 (2008) 7-10.

[15] Y.-W. Yu, C.-P. Cho, T.-P. Perng, Nanoscale Res Lett, 4 (2009) 820-827.

[16] K.A. Higginson, X.-M. Zhang, F. Papadimitrakopoulos, Chemistry of Materials, 10 (1998) 1017-1020.

[17] D. Yokoyama, A. Sakaguchi, M. Suzuki, C. Adachi, Organic Electronics, 10 (2009) 127-137.

[18] F.F. Muhammad, K. Sulaiman, Measurement, 44 (2011) 1468-1474.

[19] A.B. Djurišić, T.W. Lau, L.S.M. Lam, W.K. Chan, Applied Physics A: Materials Science and Processing, 78 (2004) 375-380.

[20] G.M. Credo, D.L. Winn, S.K. Buratto, Chemistry of Materials, 13 (2001) 1258-1265.

[21] M. Brinkmann, G. Gadret, M. Muccini, C. Taliani, N. Masciocchi, A. Sironi, Journal of the American Chemical Society, 122 (2000) 5147-5157.

[22] F. Auzel, G. Baldacchini, T. Baldacchini, P. Chiacchiaretta, R. Balaji Pode, Journal of Luminescence, 119-120 (2006) 111-115. 